\title{
A survey of occupational therapists' involvement in facilitating self- employment for people with disabilities
}

\author{
Luther Lebogang Monareng, BSc OT (Wits), DHT (UP) \\ Lecturer at Department of Occupational Therapy, Faculty of Health Sciences, School of Therapeutic Sciences, University of the \\ Witwatersrand.
}

ORCID-0000-000I-6780-2436

Denise Franzsen, BSc OT (Wits), MSc OT (Wits), PhD (Wits); DHT (UP)

Senior lecturer at Department of Occupational Therapy, Faculty of Health Sciences, School of Therapeutic Sciences, University of the Witwatersrand

ORCID-0000-000I-8295-6329

\section{Hester van Biljon, BOT (UFS), MSc OT (UFS), PhD (Wits)}

Sessional Lecturer, Department of Occupational Therapy, Faculty of Health Sciences, School of Therapeutic Sciences, University of the Witwatersrand.

ORCID 0000-0003-4433-6457

Background: In South Africa, occupational therapists are involved with the facilitation of people with disabilities ability to work, but the high unemployment rate in the country affects placement opportunities. Utilising the option of self-employment is a way of addressing this problem.

Objective: To explore the attitude of South African occupational therapists about facilitating self-employment with their clients, their awareness of available resources that support self-employment, if therapists are offering such intervention and what they perceive their role to be within the field.

Method: The study used a quantitative cross-sectional descriptive survey design.

Results: A positive attitude (90\%) and good awareness of available resources (74\%) existed amongst participating occupational therapists. Occupational therapy practices did not offer self-employment facilitation in an evidence-based manner. Therapists believed their roles were undefined within the field of self-employment, and their training did not equip them to offer such intervention.

Conclusion: Occupational Therapists agree that self-employment is a good work option for people with a disability and are aware of resources that support such endeavours. The therapeutic practice and role definition is lacking. Occupational therapists have to create evidence that enables transformational and afro-appropriate interventions, for example, self-employment for people with disabilities within their profession.

Key words: Self-employment, Unemployment, SMME (Small, medium and micro enterprise) and PWDs (People with disabilities)

\section{INTRODUCTION}

Eight in ten persons with a disability are unemployed in South Africa, making discrimination in terms of denial of employment opportunities one of the worst challenges faced by people living with disabilities'. This is despite two decades of legislation that protects and promotes the employment of people with disabilities (PWD) $)^{2,3}$. Discriminatory perceptions, inaccessibility of public and work spaces, insufficient access to resources, such as skills training and vocational rehabilitation, and disincentives created by disability benefits are factors that contribute towards the high rates of unemployed in PWDs ${ }^{4}$. Lack of employment adds to the burden of care and perpetuates poverty cycles for PWD ${ }^{5}$.

Breaking these cycles and creating employment opportunities for PWDs is a challenge. A possible solution to address this predicament is self-employment ${ }^{6}$, which is supported by the South African legislation. The National Small Business Act of $1996^{7}$ and the White Paper on the Development and Promotion of Small Business in $1995^{\circ}$ facilitates self-employment in small, medium and micro enterprises (SMME). Several non-governmental organisations (NGO's) also provide services in assisting PWDs to develop their own small businesses'. While the National Informal Business
Upliftment Strategy (NIBUS), which is based in the Department of Small Business Development, focuses on supporting and uplifting existing informal businesses owned by designated groups including women, youth and PWDs, they do not assist those previously unemployed to become self-employed ${ }^{10}$. According to the Disability Census (20II), over a million PWDs in South Africa are receiving government grants" due to limited employment, which ultimately affects the development of the country's economy ${ }^{12}$ and exacerbates poverty for these individuals ${ }^{13}$, their families and the society as a whole ${ }^{14}$.

A prominent occupational therapist, Prof Alfred Ramukumba ${ }^{15}$, recognises the impact of unemployment in the lives of South Africans: "Undoubtedly, the inner world of the majority of the population in South Africa is clouded by poverty and poor socioeconomic conditions and income generation is viewed as a priority. Despite their harsh realities, both urban and rural South African communities strive to improve their lives by seeking employment and participating in income generating projects"16:397. He urges South African occupational therapists to focus their approach on meeting the most important needs of their patients, which in his experience, is the ability to work. 


\section{LITERATURE REVIEW}

Occupational therapists are recognised role players in addressing the occupation of work with their clients ${ }^{17}$. In South Africa, vocational rehabilitation services provide return to work as well as training and reskilling, support groups, guidance and counselling aimed at obtaining a new position in the open labour market or sheltered and protected employment ${ }^{18}$. Challenges within South Africa encourages innovative occupational therapy practice ${ }^{19}$ and the profession has a long history of facilitating self-employment for their clients ${ }^{20}$. During the Apartheid era, segregation and discrimination limited healthcare, education and employment opportunities to black South Africans ${ }^{21}$. Occupational therapists turned to self-employment, which they called 'home industries' as work opportunities for their patients affected by Apartheid ${ }^{22}$. South African occupational therapists are still in a position to contribute towards alleviating unemployment issues by identifying potential and encouraging entrepreneurship and self-employment opportunities amongst $\mathrm{PWDs}^{23}$.

In order to support transformation in the profession, occupational therapists, such as Lorenzo ${ }^{13,24}$ and $\mathrm{McClure}^{25}$, indicate the need for a move towards a more Afrocentric view of work and better response to issues of human rights that were previously violated in this country. Coetzee et $\mathrm{al}^{5}$ notes that occupational therapists need to adapt to apply vocational rehabilitation to the demographic and socioeconomic context of the country in which they work. In South Africa this should be suited to the types of employment models within a developing economy using a community-based rehabilitation model.

Occupational therapists should be more aware of self-employment opportunities in the SMME sector when considering options for PWDs, as this is more in line with the realities of South Africa where the Bureau for Economic Research reports that $20 \%$ of employment is based in 2.2 million SMMEs, most of which operate in the informal sector. These businesses are owner-run and provide self-employment ${ }^{26}$. Valodia et $\mathrm{al}^{27}$ suggested that the creation of many of these self-employment opportunities in South Africa in the informal sector was for reasons relating to financial survival. Individuals who are unable to become part of the mainstream economy run informal, small and micro businesses.

A literature search of South African studies yielded initiatives related to more informal types of employment, including self-employment, and finding or starting stipendiary occupation as an alternative to seeking paid employment ${ }^{18,28}$. Facilitating self-employment was not considered as part of their professional competencies by experts in vocational rehabilitation training for occupational therapists in South Africa, as suggested by Buys in $2015^{18}$.

This suggests that although occupational therapists may be aware of the need to address the plight of unemployment by empowering communities through starting small businesses, there is still no clear documentation stipulating what the occupational therapists' role is in facilitating or encouraging self-employment amongst PWDs. In addition there is a dearth of documented evidence supporting occupational therapists involvement in facilitating self-employment for PWDs.

The purpose of this study was to determine South African occupational therapists' attitudes, practice and perceived roles in facilitating self-employment amongst PWDs, as well as their awareness of resources that PWDs can access for entrepreneurial endeavours in starting their own businesses.

\section{METHOD}

\section{Study design}

The researcher used a once-off quantitative cross-sectional descriptive survey design, without a follow up.

\section{Population and Sampling}

All occupational therapists who were members of the Occupational Therapy Association of South Africa (OTASA) and Rural Rehab
South Africa (RuReSa), and who were practicing across all fields of occupational therapy, received an invitation to take part in the study and complete the survey. To target occupational therapists in the vocational rehabilitation and medicolegal fields, those working in public or private practices were approached at interest group meetings and invited to complete the questionnaire. Convenience sampling was used.

\section{Data Collection}

The researcher developed an online self-administered questionnaire using the REDCap software tool. The questionnaire consisted of two sections. Section one sought demographic information such as age, gender, qualifications and years of experience in the field of self-employment, while section two consisted of both open- and close-ended questions. The questions covered the therapists' attitude towards facilitating self-employment in South Africa and if they were facilitating this option amongst PWDs. Questions about their awareness of any resources accessible for entrepreneurial endeavours required for self-employment, as well as questions about their perceived role in this area of practice, were included.

The online self-administered questionnaire was piloted on four occupational therapists who were currently working in, and had postgraduate qualifications in the field of vocational rehabilitation. Additional questions ${ }^{29}$ were added according to the experts' suggestions and the questionnaire achieved a content validity index of $91.8 \%$ based on their input.

An email was sent to all participants, using the OTASA and RuReSa emailing systems, as well as individually to therapists attending vocational rehabilitation interest groups. The email consisted of an information sheet with information about the research, and an invitation to occupational therapists inviting them to take part in the study. The email also had a link to the online self-administered questionnaire for the occupational therapists to complete. To ensure high return rates of the completed questionnaires, the researcher set a deadline of two weeks $s^{30}$; this was extended by four weeks due to the unfavourable return rate and non-respondents were sent a reminder e-mail.

\section{Data analysis}

The data from the survey questionnaire were analysed using descriptive statistics, including percentages, frequencies and measures of central tendencies. Demographic factors of therapists who reported that they were or were not facilitating self-employment in PWDs were also analysed using Mann-Whitney $U$ tests. Content analysis was used to analyse the open-ended questions and the number of responses were analysed according to frequencies for which percentages were calculated.

\section{Ethical considerations}

All participation was informed, voluntary and without remuneration. The researcher received ethical clearance from the University of the Witwatersrand's Human Research Ethics Committee (HREC) prior to conducting this study. The ethics clearance number for this study is MI60953. REDCap is a survey creator which - amongst other functions - provides a link to the questionnaire via email to the participants, which is returned anonymously via a web page; thereby ensuring participant anonymity ${ }^{31}$.

\section{RESULTS AND DISCUSSION}

Eighty-seven responses were received from the 2420 emails forwarded to occupational therapists, at a return rate of $3.6 \%$. The low response may be reflective of the 256 occupational therapists working in vocational rehabilitation identified by Buys (20I5) in South Africa ${ }^{18}$. The above therapists are involved in functional capacity assessments and vocational rehabilitation, which focus on return to work and work placement of individuals with disabilities rather than facilitating self-employment.

The therapists who responded were representative of the gender distribution of occupational therapists in South Africa ${ }^{31}$, 
with $96 \%$ being female and $4 \%$ male. Most of the participants (53\%) were between the ages of 20 and 30 years, with $1 \%$ over the age of 60 years. More than $70 \%$ of participants had practiced as occupational therapists for less than 15 years, $35 \%$ for less than 5 years, $40 \%$ for between 6 and 15 years. Thirty two percent of participants had postgraduate qualifications, with $18 \%$ based in rural settings. Many participants (62\%) worked in the public healthcare setting, with $32 \%$ in the private healthcare setting; $4 \%$ worked for non-profit organisations and $2 \%$ for non-governmental organisations. The participants were representative of all eight training centres offering occupational therapy in South Africa.

The results of the survey will be discussed as they relate to the four objectives of the study:

* To explore the attitude of occupational therapists towards facilitating self-employment amongst PWDs.

* To gauge the awareness of occupational therapists of resources that PWDs can access for entrepreneurial endeavours in starting their own businesses.

* To establish if occupational therapist are participating in facilitating self-employment amongst PWDs.

* To enquire what occupational therapists perceive their role to be in facilitating self-employment amongst PWDs?

\section{Attitude of occupational therapists about facilitating self-employment for people with disabilities}

Ninety percent of the participants reported that facilitating a selfemployment option for PWDs was important due to the lack of opportunities in corporates and the formal labour market for PWDs in the current South African economy. Arguably, self-employment has the potential to empower PWDs in that it will provide a source of income. The participants indicated that self-employment could be associated with benefits for the individual and their family or community. Individual benefits included independence, meaningful life, flexibility at work, improved self-worth and esteem, health promotion and limiting the effects of disability, such as a relapse. Benefits that extend beyond the individual included active citizenship as the individual contributes positively to his family, community and economy. This may also assist in disability awareness in communities resulting in more support for PWDs.

Regarding the possibility that PWDs' dependency on the gov- ernment disability grants may reduce self-employment, $4 \%$ of the participants argued that South Africa lacks the necessary infrastructure to support PWDs in the demanding self-employment sector. These participants also argued that PWDs would rather rely on a disability grant than start a business. Although social grants provide some income security and poverty alleviation, there is evidence that a large number of PWDs would prefer to work $^{32,33}$ confirming the importance of facilitating employment and self-employment as an option for PWDs.

\section{Awareness of resources that people with disabilities can access for entrepreneurial endeavours in starting their own businesses}

The majority $(74 \%)$ of respondents reported they were aware of self-employment opportunities in the context in which they work, especially those in urban settings. They provided examples of these opportunities, which were categorised as retail, service and skills and manufacturing/production (Table I below). Twenty six percent $(26 \%)$ of the participants reported that they were aware of self-employment opportunities especially in the low resourced communities, however a greater percentage (45\%) highlighted they were unaware of resources available to assist them in facilitating self-employment amongst PWDs. The rest of the participants provided information on the resources they felt were worth accessing within governmental departments, educational and private/Non-profit Organisations/Non-Government Organisations (Table II on page 55).

\section{Occupational therapist practicing the facilitation of self-employment amongst PWD}

More than half $(53 \%)$ of occupational therapists reported they had no experience in facilitating self-employment for PWDs as their focus was on vocational rehabilitation such as work hardening, return to work and training clients in job seeking skills. Some highlighted a lack of exposure to this option, lack of awareness of possibilities in SMMEs and their work setting not being conducive to the exploration of self-employment with PWDs. Sixty nine percent of participants did not feel sufficiently skilled or trained to facilitate self-employment amongst PWDs, because their undergraduate studies instil the culture of preparing PWDs for sheltered employment and not encouraging PWDs to explore the self-employment option. However only $21 \%$ of these participants were in support of further training to ensure occupational thera-

Table I: Opportunities for self-employment categorised as retail, service and skill, and manufacture/production

\begin{tabular}{|c|c|c|}
\hline Retail & Service \& Skills & Manufacturing/Production \\
\hline \multirow[t]{2}{*}{$\begin{array}{l}\text { - Spaza shops (e.g. selling of } \\
\text { airtime, cigarettes) } \\
\text { - Second hand clothing } \\
\text { - Artwork } \\
\text { - Blankets } \\
\text { - Vendor (e.g. at taxi rank, } \\
\text { outside school, street } \\
\text { pavements etc.) } \\
\text { - Coffee shop }\end{array}$} & $\begin{array}{l}\text { - Freelancing } \\
\text { - Repairs (e.g. computers, cell-phone) } \\
\text { - Administrative duties (e.g. Internet café, Transcriber) } \\
\text { - Repairs (wheelchairs, electronics) } \\
\text { - Hair salon } \\
\text { - Sewing } \\
\text { - Car wash } \\
\text { - Laundry services } \\
\text { - Driver (e.g. Uber) } \\
\text { - Information Technology (IT), photography, web developer, delivery service } \\
\text { - After school care services } \\
\text { - Domestic work (gardening/maintenance) } \\
\text { - Tekkie wash } \\
\text { - Educating PWDs in se } \\
\text { - Child minding } \\
\text { - Management of small security company } \\
\text { - Dog walker } \\
\text { - Tutoring } \\
\text { - Plumbing } \\
\text { - Catering } \\
\text { - Recycling } \\
\text { - Tendering }\end{array}$ & $\begin{array}{l}\text { - Hand work e.g. } \\
\text { - Metal work } \\
\text { - Plastic weaved mats } \\
\text { - Baking } \\
\text { - Craft activities (e.g. } \\
\text { jewellery making, beading) } \\
\text { - Woodwork } \\
\text { - Toy making } \\
\text { - Carpentry } \\
\text { - Producing and selling a } \\
\text { variety of products } \\
\text { (e.g. growing and selling } \\
\text { vegetables) } \\
\text { - Dog biscuits }\end{array}$ \\
\hline & \multicolumn{2}{|l|}{ Woodwork, upholstery and shoe repairer and maker } \\
\hline
\end{tabular}


Table II: Resources for accessing as suggested by the research participants

\begin{tabular}{|c|c|c|}
\hline Government & Educational & Private/NPOs/NGOs \\
\hline $\begin{array}{l}\text { - Hospital (OT projects) } \\
\text { - Vocational Rehabilitation Task Team } \\
\text { - Funding: Department of Agriculture, } \\
\text { Disabled People South Africa (DPSA), } \\
\text { Department of Social Development } \\
\text { - Department of Social Justice } \\
\text { - Skills Education Training Authorities } \\
\text { - Department of Labour } \\
\text { - Women's Development Bank }\end{array}$ & $\begin{array}{l}\text { - Training centres } \\
\text { - Adult Basic Education and } \\
\text { Training (ABET) } \\
\text { - In service-training } \\
\text { - Gordon Institute of Business } \\
\text { Science (GIBS) } \\
\text { - Technical Vocational Education } \\
\text { and Training college }\end{array}$ & $\begin{array}{l}\text { - National Development Agency (NDA) } \\
\text { - Private sector e.g. job coaching } \\
\text { - Community projects } \\
\text { - Headway } \\
\text { - Association for People with Disabilities (APD) - for } \\
\text { sheltered employment } \\
\text { - QuadPara Association South Africa } \\
\text { - Business incubators } \\
\text { - Media (online platforms) } \\
\text { - Disability Work Forum } \\
\text { - Mainstream entrepreneur development opportunities } \\
\text { - Work Assessment Units } \\
\text { - Disport Groups } \\
\text { - Peer support }\end{array}$ \\
\hline
\end{tabular}

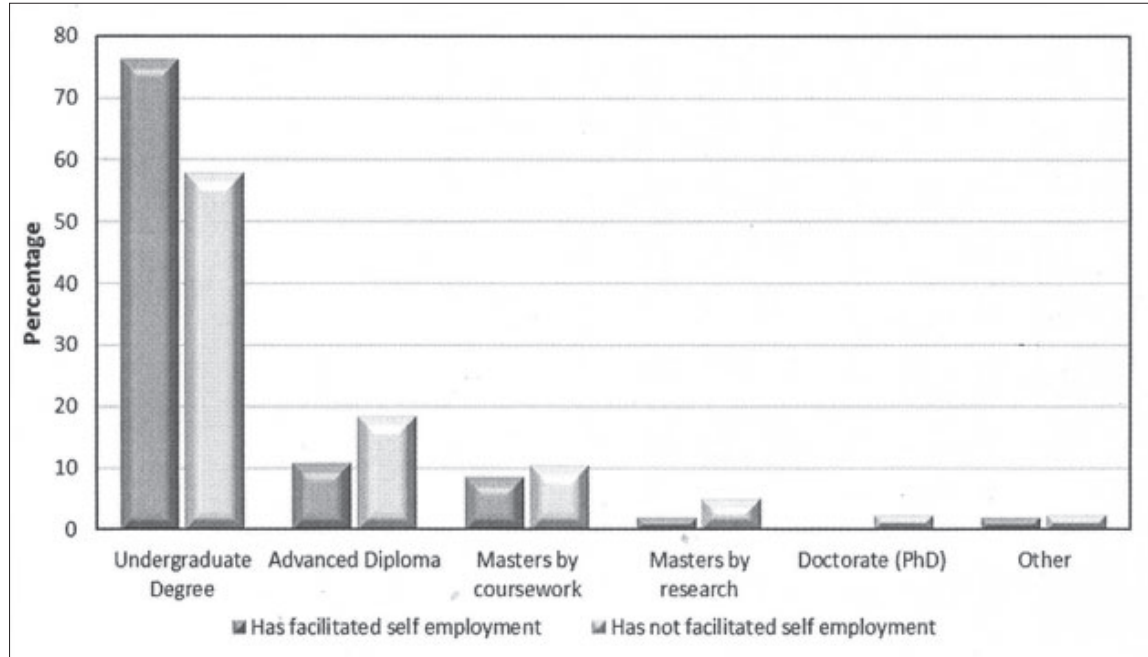

Figure I: Level of qualifications of occupational therapists facilitating and not facilitating self-employment in people with disabilities

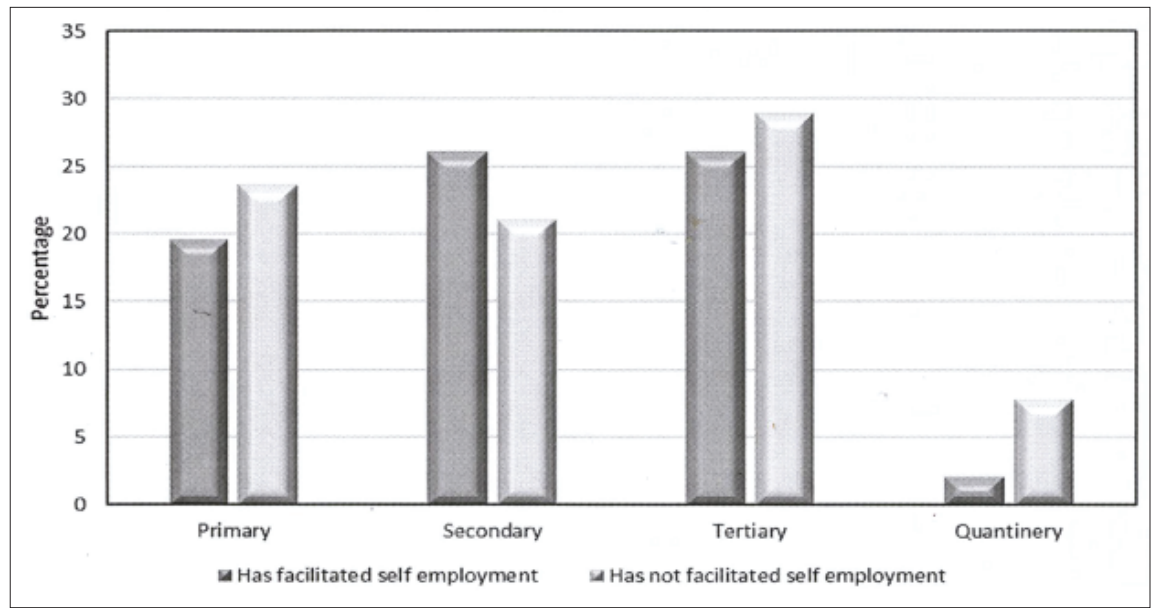

Figure 2: Level of healthcare in which occupational therapists do and do not facilitate self-employment in people with disabilities

pists feel competent in facilitating self-employment. Despite this, $43 \%$ of participants claimed they had experience in facilitating self-employment in PWDs in that they had given advice, had run income generation projects and had done prevocational training as their setting had allowed for this type of vocational rehabilitation. It would appear that these occupational therapists are not documenting their endeavours in this regard, as was noted in the literature section.

\section{Profile of occupational therapists reporting involvement in facilitating self- employment for PWDs}

The demographic factors of the occupational therapists who reported facilitating and not facilitating self-employment in PWDs were compared. The majority of those with an undergraduate qualification reported having facilitated self-employment for PWDs. South African occupational therapists with post-graduate qualifications were less likely to facilitate self-employment amongst their patients but there was no significant difference according to the level of qualification for those who did and did not facilitate selfemployment $(p=0,188)$ (Figure I).

While there was no significant difference $(p=0.688)$ in participants who did and did not facilitate self-employment for PWDs across the settings of private healthcare, public healthcare, non-governmental organisations and non-profit organisations, those who reported facilitating self-employment appeared to be clinicians based in secondary levels of healthcare (Figure 2).

Although there were no significant differences between the groups, there were differences between participants with undergraduate and postgraduate degrees. This difference may imply the lack of focus on self-employment in postgraduate studies. Occupational therapists with less than 10 years' experience are working at lower levels of care, spend more time with their patients and are positioned to address issues of self-employment. Participants with higher qualifications and more years of experience are more likely to either hold managerial and academic positions, which reduces their patient contact time, or they are providing specialised services in the private sector and thus not in day-to-day contact with unemployed PWDs. Occupational Therapists in specialised services are often self-employed themselves and need to generate an income from their therapeutic interventions in order to run a financially viable practice. As there is no funding for facilitating self-employment with PWD's, who usually have not been previously employed, an occupational therapist who is self-employed in private practice will find it difficult to incorporate a viable business model. 


\section{The perceived role of occupational therapy in facilitating self-employment in PWDs}

When indicating the role of occupational therapists in facilitating self-employment with PWDs, participants felt that since selfemployment was not unique to occupational therapy, this aspect of vocational rehabilitation needed a team approach. Participants suggested that further training and experience would better position occupational therapists to contribute in facilitating this option for PWDs.

Although 10\% of the participants were indifferent, $20 \%$ maintained that occupational therapists are sufficiently skilled to facilitate self-employment amongst PWDs. They felt their undergraduate training entailed acquisition of knowledge on models such as that of the Vona du Toit's Model of Creative Ability. Such models provide guidance for occupational therapists in determining a patient's level of motivation and action, which is important in activity selection or handling of a particular patient, which may be important when suggesting the self-employment option. Participants highlighted that although physical function is important in being self-employed, psychosocial factors, such as motivation to start and maintain a business, are far more significant. Regardless of the above, $75 \%$ of the participants indicated their unemployed patients were willing or would be willing to consider self-employment, especially the young and/or unskilled.

Participants also identified limitations and challenges to facilitating self-employment for PWDs. The challenges PWDs may face were summarised as lack of skills, limited education, limited knowledge, lack of motivation and impairments from the disability, low self-esteem, competing with able-bodied people, ignorance and lack of awareness of available resources. External factors identified were the poor economic status of South Africa, limited opportunities in the communities, inadequate resources (finance to start a business), stigma, inadequate security and crime, poor necessary support systems and families being over-protective of PWDs resulting in them assuming a sick role.

\section{RECOMMENDATIONS}

A scope of practice statement on the role of occupational therapy within the context of self-employment would guide occupational therapists involved with PWDs who could benefit from selfemployment. It might also increase the level of self-employment facilitation amongst occupational therapists.

Therapists, who engage in the facilitation of self-employment, need encouragement and support to document their work and in so doing, contribute towards building evidence on which to base future practice. In addition their effort should be supported to involve venture capitalists, gain access to government funding for the facilitation of projects, involving corporates to engage as part of their corporate funding, or getting occupational therapists involved in structures which are already set up such as those supported by religious organisations or NGO's.

In the training spectrum, the profession's awareness of selfemployment as a placement option for PWDs needs fostering amongst undergraduates and more postgraduate research in the field needs to be encouraged.

\section{Limitations of this study}

Limitations of the study include the small sample and low response rate. The population sample was also drawn from two organisations that are made up of voluntary membership and the views reported in this study may not reflect those of occupational therapists not affiliated.

\section{CONCLUSION}

South African occupational therapists have a positive attitude towards self-employment as an option to place their patients in the labour market. They are also aware of the resources available to assist self-employment even though the latter focuses primarily in urban areas. In addition, the occupational therapy profession is ideally positioned to facilitate self-employment as work options for PWD's. Despite this, the practice of self-employment facilitation is sparce and adversely affected by a lack of empirical evidence, training and role consensus. The profession needs to prioritise its involvement in the facilitation of self-employment. This afro-relevant approach holds transformational potential for the profession, occupational curative value for PWDs and benefits the country as a whole.

\section{ACKNOWLEDGEMENT}

As the main author, I wish to thank the University of the Witwatersrand's eLearning team, vocational rehabilitation clinicians and the University of the Witwatersrand Faculty of Health Sciences for start-up funding, which made this research a success.

\section{REFERENCES}

I. Africa SS, Lehohla P. Census 20 I I: Profile of Persons with Disabilities in South Africa: Statistics South Africa; 2014.

2. Republic of South Africa. Labour Relations Act (No 66 of 1995), (1995).

3. Republic of South Africa. Employment Equity Act, (No 55 of 1998) Code of good practice, 1998.

4. Organization WH. Chapter 8 Work and employment. http://www. who.int/disabilities/world_report/20 I I/chapter8.pdf; 201 I

5. Coetzee Z, Goliath C, van der Westhuizen R, Van Niekerk L. Reconceptualising vocational rehabilitation services towards an intersectoral model. South African Journal of Occupational Therapy. 20II; 4I(2): 32-7.

6. Bendile D. Ramaphosa encourages entrepreneurship among young South Africans Johannesburg: Eyewitness News; 2016 [updated 2016 February 21; cited 2016 Nov 15. Available from: http:// ewn.co.za/20I6/02/2I/Ramaphosa-encourages-entrepreneurshipamong-young-South-Africans\#.

7. Republic of South Africa. National Small Business Act, no 102 of 1996. In: Gazette G, editor. Pretoria; 1996.

8. Industry DoTa. White Paper on National Strategy for the Development and Promotion of Small Business in South Africa In: Gazette G, editor. Pretoria; 1995.

9. Khasnabis C, Heinicke MK, Achu K, Al Jubah K, Brodtkorb S, Chervin $P$, et al. Community-based rehabilitation: CBR guidelines: World Health Organization; 2010

10. Development DoSB. The National Informal Business Upliftment Strategy (NIBUS) Pretoria20 I 4 [Available from: http://webcache. googleusercontent.com/search?q=cache:VHB2N02QGLIJ:www. dsbd.gov.za/\%3Fpage_id\%3D | 224+\&cd = I \&hl=en\&ct =clnk\& $\mathrm{gl}=\mathrm{za}$.

I I. Ferreira L. Factsheet: Social grants in South Africa - separating myth from reality. South Africa; 2017; February 28.

12. Statistics South Africa. Census 20 I I: Profile of persons with disabilities in South Africa Pretoria: Statistics South Africa; 2014. Contract No.: Report No. 03-0I-59.

13. Lorenzo T, van Niekerk L, Mdlokolo P. Economic empowerment and black disabled entrepreneurs: negotiating partnerships in Cape Town, South Africa. Disability and Rehabilitation. 2007; 29(5): 429-36.

14. Davies R, Thurlow J. Formal-Informal Economy Linkages and Unemployment in South Africa. South African Journal of Economics. 2010; 78 (4): 437-59.

15. Ramukumba TA. The 23rd Vona du Toit Memorial Lecture 2nd April 2014. Economic Occupations: The 'hidden key' to transformation. South African Journal of Occupational Therapy. 20I5; 45(3): 4-8.

16. Abasa E, Ramukumba TA, Lesunyane RA, Wong SKM. Globalization and Occupation: Perspectives from Japan, South Africa, and Hongkong. Christiansen C, Townsend E, editors. New Jersey: Pearson; 2010

17. Adam K, Gibson L, Lyle A, Strong J. Development of roles for occupational therapists and physiotherapists in work related practice: an Australian perspective. Work. 2010; 36(3): 263 - 72.

18. Buys T. Professional competencies in vocational rehabilitation: Results of a Delphi study. South African Journal of Occupational Therapy. 20I5; 45(3): 48-54 
19. Du Toit SHJ. Using the Model of Human Occupation to Conceptualize an Occupational Therapy Program for Blind Persons in South Africa. Occupational Therapy in Healthcare. 2008; 22(2): 5I-6I.

20. Cawood J. Vegetable gardening as a home industry for patients confined to wheelchairs. South African Journal of Occupational Therapy. 198I; I I(I): 3-5.

21. Phatlane SN. Poverty, health and disease in the era of high Apartheid: South Africa, 1948 - 1976. Pretoria: UNISA; 2006.

22. McLaren P. Basic shoe repairing as a home industry for the African paraplegic South African Journal of Occupational Therapy. 1977; $7(1):$ I0-I.

23. Ross J. Occupational therapy and vocational rehabilitation: John Wiley \& Sons; 2013

24. Lorenzo T. Three Elephants in three decades of occupational therapy and research, equity, evolution and evidence Cape Town, Western Cape, South Africa2008 [Available from: https://www.ufs.ac.za/ docs/librariesprovider25/occupational-therapy-documents/all-documents/three-elephants-tlorenza-292-eng.pdf?sfvrsn=ddd5f72। 0 .

25. McClure P. Developing entrepreneurial skills in occupational therapy students. British Journal of Occupational Therapy. 20II; 74(II): 499.

26. Research TBfE. The Small, Medium and Micro Enterprise sector of South Africa. Stellenbosch University; 2016 January.

27. Valodia I, Davies R, Altman M, Thurlow J. Economic behaviour in South Africa's informal economy'. Report to the conflict and governance facility (CAGE) Pretoria: Human Sciences Research Council. 2007.

28. van Biljon HM, Casteljien D, du Toit SH, Soulsby L. Opinions of occupational therapists on the positioning of vocational rehabilitation services in Gauteng Public Healthcare. South African Journal of Occupational Therapy. 2016; 46(I): 45-52.

29. Yaghmale F. Content validity and its estimation. Journal of Medical Education. 2009; 3(I): 25-7.

30. Burns KE, Duffett M, Kho ME, Meade MO, Adhikari NK, Sinuff T, et al. A guide for the design and conduct of self-administered surveys of clinicians. Canadian Medical Association Journal. 2008; 179(3): 245-52.

31. World Federation of Occupational Therapists. WFOT Human Resources project 20162016 [Available from: https://www.apeto.com/ assets/vision-international-de-los-recursos-humanos-to-2016.pdf.

32. Surender R, Noble M, Wright G, Ntshongwana P. Social assistance and dependency in South Africa: An analysis of attitudes to paid work and social grants. Journal of Social Policy. 20I0; 39(2): 203.

33. Graham L, Moodley J, Ismail Z, Munsaka E, Ross E, Schneider M. Poverty and Disability in South Africa Johannesburg: The Centre for Social Development in Africa (CSDA); 2014.

\section{Corresponding Author}

\section{Luther Monareng}

Email: luther.monareng@wits.ac.za 